\title{
Perceptions of Students towards Black South African English in a Science and Science University Community
}

\author{
Noel Manganye \\ Thembinkosi Mabila* \\ University of Limpopo, Turfloop Campus - South Africa. \\ Thembinkosi.Mabila@ul.ac.za
}

Doi:10.5901/mjss.2014.v5n23p1479

\begin{abstract}
In this paper we reflect on Black South African English (BSAE) as a recognised variety in the new Englishes paradigm. The aim of the paper is to report on Science and Mathematics students' perceptions and towards BSAE. A qualitative-quantitative mix approach was elected to elicit responses from a group of 23 Science and Mathematics students. Respondents were required to complete a perceptions questionnaire as well a feature recognition test. The results of a combination of statistical (frequencies) and thematic analysis show that learners recognise and prefer BSAE. Therefore, considering the fact that the results of this study indicate (1) positive perceptions (2) general preference of BSAE in the learning of Science and Mathematics, our article concludes with a decisive concurrence with evolving recommendations of the institutionalisation of BSAE as an indigenised variety of English.
\end{abstract}

Keywords: Black South African English, World Englishes, Varieties, Multilingualism

\section{Introduction}

The focus of this article is on Black South African English (BSAE). BSAE is increasingly receiving attention within what has come to be known as the New Englishes paradigm. This paradigm makes provision for non-standard English varieties learned in former British colonies as legitimate Englishes in their own rights. It is in this connection that BSAE a variety of English spoken by mother-tongue speakers of indigenous African languages in South Africa has recently been subjected to empirical research. Whereas there is no general agreement on the status of BSAE, studies show that it is an institutionalised variety (Makalela, 2007; Kasanga, 2006; Parkinson \& Singh, 2007); sharing grammatical and pragmatic patterns with South African indigenous languages (Buthelezi, 1995; Gough, 1996 and Makalela, 2004).

Even though it is an institutionalised variety, students who use BSAE properties in institutions of higher learning are vulnerable to high failure rate due to the difficulties they have with Standard British English (SBE) norms used in the South African education system. To this Stepanek $(1989$, p1) states that "a lack of proficiency in the language of instruction has a harmful effect on a student's ability to deal with content-area texts, word problems and lectures". This means that students require knowledge of the language of instruction in order to perform well in their studies and develop cognitive skills. It also implies that students' ability to participate in content subject such as Science and Mathematics is dependent on their language ability: speaking, listening, reading and writing (Buxton, Allexsaht-Snider, \& Rivera, 2012; Lee \& Fradd, 1998). However, the use of SBE norms, which are culturally distant to the students, tend to exacerbate the problem of comprehension and failure, especially in Science and Mathematics.

Noting that language should be a bridge rather than a barrier to learning and doing subjects such as Science and Mathematics (Warren, Ballenger, Ogonowki, Rosebery, \& Barnes, 2001), an alternative way of using BSAE to teach in African classrooms is called for in the South African education system. Nthakana (2000:14), for example, calls BSAE "Peoples' English" which she says 'is a variety of English which is being put forward by some as an alternative to the standard-which takes standard southern SBE as a norm'. However, little is known about attitudes of BSAE speakers towards the use of the localized English in a formal domain. It is against this background that the study sought to investigate the perceptions of Science and Mathematics students towards BSAE as an alternative variety for learning Science and Mathematics. So the study reported in this article also sought to achieve the following objectives: First, to assess the recognition and preference of BSAE features by Science and Mathematics students. Second, to determine the perceptions of students towards the use of BSAE as an alternative medium in the learning of learning of Science and Mathematics. 


\section{Theoretical Considerations}

BSAE as a distinctive variety can be understood within the framework of World Englishes. Kachru (1985) classifies English speakers into three distinctive concentric circles: The inner circle; the expanding circle, and the outer circle (or extended circle). In the classification of the Kachruvian (1985) concentric circles model, the inner circle refers to the traditional bases of English countries where it is the primary language e.g. the United States of America, United Kingdom, Canada, Australia and New Zealand. English in these countries is norm-providing, they have traditionally been recognized as models since they are used by the native speakers. The expanding circle includes countries such as Japan, China, Saudi Arabia, Korea, Russia, etc. In this circle English is norm-dependent.

To understand the function of English in this circle requires recognition of the fact that English is an international language, and that it has already won the race in this respect with linguistic rivals such as French, Spanish and Russian (Sato \& Suzuki, 2007). The geographical regions characterised as the expanding circle do not necessarily have a history of colonisation by the users of the inner circle. The outer circle is an earlier phase of the spread of English and its institutionalisation in non-native context. The political histories of the regions where institutionalised varieties are used have many shared characteristics: these regions have gone through extended period of colonisation by the users of the inner circle varieties. The outer circle forms a large speech community with great diversity and distinct characteristics. The major features of this circle are that: First, English is thought to be one of two or more codes in the linguistic repertoire of such bilinguals or multilinguals and second, [it] has acquired an important status in the language policies of most multilingual nations (Kachru, 1992). This circle includes countries such as Nigeria, Swaziland, Ghana, Malawi, Zambia, Zimbabwe and South Africa. The English used in these countries are norm-developing varieties (the outer circle). In countries using these varieties there has been a conflict between linguistic norm and linguistic behaviour. The study reported in this paper is concerned with the outer circle which includes BSAE as a new form of English. In other words BSAE is positioned within the outer circle of World Englishes.

\section{The Context of English in South Africa}

In view of the global status of English, the rapid increase in the number of non-native speakers of English in and beyond the outer circle is a significant development (Geay, McNally \& Telhaj, 2013; Kasanga, 2005; Makalela, 2004; Nthakana, 2000). As a direct consequence, emerging varieties of English have developed, which are local varieties other than those spoken natively (Kachru, 1985).

The expansion of English has prompted the use of labels such as global language or world language (Gage, 1986; Crystal, 1997 and Kasanga, 2005) as it fulfils a subtle role as one of the vehicles of globalisation, together with international trade, travel, and tourism, multilingualism, the internet, mass media, and even the promotion of popular culture through film and music (Berns, 2005; Pennycook, 2003). The factors which contribute to the spread of English have been the subject of much debate. Some denounce English as a product of linguistic imperialism by colonial imposition, while others see the appeal of English as the main factor in its rapid expansion through macro-acquisition through deliberate, conscious choice by individuals for practical, utiliteral purposes (Brutt-Griffler, 2002).

English came to Southern Africa as a result of colonisation of Southern African countries-Botswana, Lesotho, Malawi, South Africa, Swaziland and Zimbabwe by Britain more than a century ago (Kamwangamalu \& Chisanga, 1997). Its history dates back to the arrival of the British at the Cape in 1806. It took root as a southern African language as a result of the settlement of 1820 in the Eastern Cape and 1848-1862 in Natal, and of the flux to the diamond mines of Kimberly in 1870 and the gold mines of the Witwatersrand in 1886. As in most of the countries in the world where it serves as lingua franca, English came to be perceived as the language of social elite to most of Southern Africa. In South Africa, as Silva (2005) points out, English was seen as the language of aspiration and empowerment for black South Africans and for many Afrikaners. However, from the time the National Party came to power in 1948, English became the other official language as all government official processions and administration were exclusively in Afrikaans. Afrikaans was allocated resources for development while English was given a lesser status and African languages were not considered at all. Despite the treatment, from 1948-1994, English was too powerful to be adversely affected as it retained its dominance as the language of higher education, commerce, Science and technology, and as the internal and international language of communication (Silva, 2005).

Post 1994, English has remained one of the eleven official languages in South Africa. Although, the position of South African English is different from that in multilingual but predominantly English-speaking countries (Australia, New Zealand, Canada, and United States of America) for two reasons: First, mother-tongue English-speakers are very few in South Africa. Second, there is the potential for influence by many more divergent languages than in other English- 
speaking communities, as in South Africa English is in contact with atleast nine Indigenous languages. These indigenous languages are Nguni in the east (namely, IsiZulu, IsiXhosa, SiSwati \& IsiNdebele), SeSotho in the central and northern areas (namely, SeSotho, SeTswana \& SeSotho sa lebowa) and two other languages in the far north are not related to the Nguni and Sotho groups, namely Xitsonga and Tshivenda.

\section{The Emergence of BSAE}

Amongst the 'multiple forces' which underlie the emergence of BSAE, education and media are singled out (Kasanga, 2005). However, of these forces the socio-educational context is perhaps the most influential. Makoni (1993) believes that socio-political forces have acted as catalysts in the development of New Englishes. In South Africa, the Soweto uprising was followed by a collapse of education for black South Africans. When the system of education for blacks reverted to the use of English as a medium of instruction, the demand for instruction in English became so overwhelming that it was left in the hands of under-qualified teachers in black schools (Titlestad, 1997). As a result, the teaching of English as a second language has been in the hands of non-native speakers of the language who have often been unqualified or under-qualified for the task (Buthelezi, 1995). This led to learners acquiring incorrect English language forms which got fossilised (De Klerk \& Gough, 2002). Hence, both (Buthelezi, 1995; De Klerk \& Gough, 2002) view the occurrence of nonstandard English features as teacher-induced.

Media is one of the forces that underlie the emergence of BSAE. Print media, especially daily newspapers run by BSAE speakers, for example Sowetan and The Star newspapers remain outlets for the educated BSAE speakers to express themselves and a source of inputs for the readership. Kasanga (2005) states that innovations in BSAE found in these media, including borrowings from African languages, such as concepts like toyi toyi to demonstrate at the rhythm of toyi toyi, a famous South African dance associated with black political protest and defiance, and coinages, such as condomise, adopted in the HIVIAIDS ABC (Abstain, Be faithful, Condomise) campaign, have contributed to the emergence of BSAE as a distinct variety. Besides being sources of input for their audience and instrument for consolidation of the variety, the wide circulation of these media contributes to the acceptance of the forms which they popularise.

In another explanation, Mothoa (2001) links the emergence of BSAE to the concept of overgeneralisation. A concept which refers to a state in which learners overgeneralise those aspects of language that they find easy to learn. Since these aspects are easy, they are used even in inappropriate contexts. For example, the regular past tense marker 'ed' to irregular verbs such as the word 'cut'. Instead of using the past form cut in past tense context, learners create nonstandard construction like cutted (Mothoa, 2001). However, Makalela (2004) indicates that the emergence of BSAE is a result of creative bilingualism. For instance, its speakers juggle between two linguistic systems and creatively produce a well-formed and rule governed variety of English. The article departs from the common held view of overgeneralisations as foundations to creative use of mother tongue transfer.

The emergence of BSAE is also attributed to the role of transfer of linguistic structures from indigenous African languages (Makalela, 2004). This account finds its roots in second language acquisition theories. Rod Ellis is one of the key scholars in second language acquisition who wrote broadly about language transfer. In his classic The Study of Second Language Acquisition Rod Ellis explores language transfer. Language transfer according to Ellis (1994) refers to the incorporation of features of the first language L1 into the knowledge system of the second language (L2) which the learner is trying to build. Both translation and borrowing, the use of the L1 to deal with communication problems are examples of communication transfer, as are code-mixing; the use of both the L1 and L2 in the construction of the same sentence and code switching and the use of the L1 and L2 within a discourse. Ellis (1994) states that evidence for transfer in all aspects of language - phonology, syntax, semantic, and pragmatics is now abundant.

\section{Research Design}

Within the qualitative-quantitative mix paradigm (Creswell, 2003), the study reported in this article took the form of exploratory design to investigate perceptions of students towards the use of BSAE in the learning of Science and Mathematics. The exploratory design was relevant for this study since speaker perceptions towards BSAE has not been previously studied in BSAE research.

\subsection{Research Site}

The research site of this study was a historically black university campus in Limpopo province South Africa. 


\subsection{Population and Sampling}

From a total population of 180 possible participants who all possessed homogenous qualities convenience sampling was used in this study (Gall, Borg \& Gall, 1996) to select 23 participants. All the students were admitted to study towards a Science and Mathematics degree in the Faculty of Science, Health and Agriculture at the University. The students can be described as previously disadvantaged (Mabila, Malatje, Addo-Bediako, Kazeni, Mathabatha, 2006). All the students were considered not qualifying for direct entry into degree studies and as such were admitted through a foundation programme which sought to increase the quality and quantity of Science and Mathematics graduates. The majority of the participants came from remote rural areas of Limpopo and Mpumalanga provinces of South Africa and speak amongst others Xitsonga, Tshivenda, Sesotho sa Lebowa and SiSwati as their first languages. Therefore, they form an ideal population who might have had standard English norms as a barrier to their academic success.

\subsection{Instruments}

The data were collected by means of a questionnaire, for perceptions towards BSAE and a Feature Recognition Test (FRT). The questionnaire consisted of closed and open-ended questions which enabled the participants to provide information, in both controlled and unrestricted manner, on the perceptions towards BSAE. The FRT sought to determine the degree to which the participants recognise features of BSAE. The test consisted of sentences with features of BSAE as pointed out in several research works (see Gough, 1994; Buthelezi, 1995; McEwan, 1992; Moyo, 1994; De Klerk and Gough, 2002 and Makalela, 2004). These included amongst others: Retention of question word order; the extension of the progressive aspect to stative verb; preposition usage in prepositional verb; topicalisation; discourse markers.

\subsection{Data Analysis}

The data collected through the questionnaire and the FRT were analysed for frequency counts. A chi-square was an ideal method to delineate expected values from the actual values and to measure the degree of difference at a $p$-value of 0.05 . As already indicated, these data were summarised through frequency graphs, with percentage used where appropriate. The responses from the open-ended questions were analysed thematically following the thematic analysis procedure recommended by (Braun \& Clarke, 2006). This procedure entails six steps which can be summed up as follows: Becoming familiar with the data; Coding; Searching for themes; Reviewing themes; Defining themes; and writing up.

\subsection{Results and Discussion}

In presenting the findings of the data analysis which was undertaken in this study, we first deal with the results of the assessment of students' perceptions on black South African English which yielded was based on the following five major features (categories) identified as peculiar to BSAE (Gough, 1994; Buthelezi, 1995; McEwan, 1992; Moyo, 1994; De Klerk and Gough, 2002 and Makalela, 2004).

\section{Recognition of Black South African English}

As already pointed out in section 5.5 above, the five major features of BSAE include: The retention of question word order (RQWo); The extension of the progressive aspect to stative verb (ExSv); Preposition usage in prepositional verb (PuPv); Topicalisation (Tpc); Discourse markers (DM) (see Gough, 1994; Buthelezi, 1995; McEwan, 1992; Moyo, 1994; De Klerk and Gough, 2002 and Makalela, 2004). The FRT which sought to assess the recognition of BSAE presented the students with various sentences carrying the various features, and thereafter asked if they thought such statements would in their view be understandable if used in Science and Mathematics. The respondents had to answer Yes or NO. The results of the assessment are presented hereunder in figure 1 which summarises all the categories. 


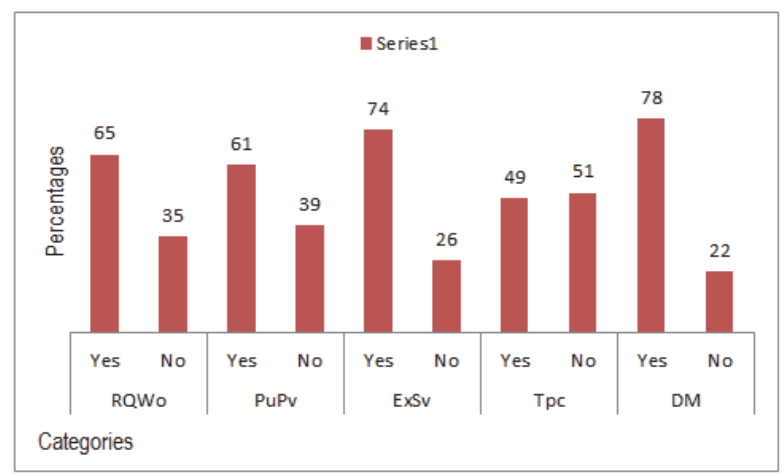

Figure 1: Recognition of BSAE features

\subsection{Retention of Question Word Order}

In this section respondents were asked if their understanding of questions in Science and Mathematics would be enhanced through the use of the question word order formation, typically used in BSAE. An example of the question word order forms as used in the questionnaire is illustrated in excerpt (1) below:

Excerpt (1): IHe asked youme why didn't youl measure mass correctly because according to me I can say that you can be able to do a good job on measurements.

Participants' responses show that they judged the question word order form grammatically correct and that they would prefer its use in their questions in Science and Mathematics. Figure 1 above shows that $65 \%$ of all the respondents agreed that the use of the retention of question word order in their Science and Mathematics content would enhance their comprehension. Only 35\% did not think that retention of question word order would have any bearing on their understanding of the content. The results point out that the majority of the respondents believe that the use of this BSAE feature, retention of question word order, would enhance their understanding and that it is a preferable syntactic structure.

Previous studies on retention of question word order in BSAE (for example, De Klerk and Gough, 2002; Makalela, 2004) revealed that it is an institutionalised syntactic structure. The grammatical judgement of the learners in the study may be attributed to the fact that this feature is widely used in BSAE and as such familiar and understandable to them. This study shows that this feature is not only institutionalised, but also a preferable expression in Science and Mathematics classes.

\subsection{Extension of progressive aspect to stative verb}

Extension of progressive aspect was another category used in the assessment of the recognition and preference of BSAE features by the respondents in this reported study. An example of the extension of progressive aspect to static verb form as used in the data collection questionnaire is illustrated below in excerpt (2):

Excerpt (2): They are not knowing getting goodthe results in their chemistry experiments because they are having two research assistants who are lazy to give advices.

The students' responses on the statement which presented the extension of progressive aspect to static verb feature are represented in figure 1 which shows that $61 \%$ of the respondents did not make a distinction between static verb and action verb. The respondents were not aware that most static verbs do not use the -ing verb ending in SBE. In BSAE static verbs can take the form of action verbs without any bearing and as the respondents prove would enhance the comprehension in students' learning. Only $49 \%$ did not think that the use of static verb would have any bearing on their understanding of the content. The results show that the majority of the respondents believe that the use of this BSAE feature in learning Science and Mathematics is.

Previous research on this aspect shows that its use in BSAE is the results of influence from indigenous African languages (Makalela, 2004; Van Rooy, 2006). Hence, Makalela (2004) claims that the Bantu temporal logic 
fundamentally exaggerates the production of this feature through transfer of temporal reasoning. In simple terms the word know is a static verb which means that it cannot take the suffix -ing to express progressive meaning. As the respondents of the present study confirm, the use of this aspect is a well understood and preferred norm in BSAE.

\subsection{Preposition usage in prepositional verb}

Also represented in figure 1 are the responses of the participant students' recognition and preference of the preposition usage in prepositional verb feature. An example of the preposition usage in prepositional verb form as was used in the questionnaire is illustrated below in excerpt (3) of the questionnaire:

Excerpt (3): getting goodWhat makes them to stop thinking about Mathematics operations is that they rely on calculators.

From the above figure 1 it is evident that $74 \%$ of the respondents agreed that the prepositional verb form used in excerpt (3) is correct, whereas $26 \%$ indicated that it is not correct. The results point out that the majority in this section believe that the use of this BSAE feature, prepositional verb form, would enhance their understanding in learning Science and Mathematics content. Although in their previous study which investigated the stability of this grammatical feature, Parkinson and Singh (2007) did not make any significant inference, they remarked that preposition usage in prepositional verb already had a high level of replacement by the standard form in an earlier test which they conducted. Hence, Parkinson and Singh conclude that there is little room for improvement among South learners when it comes to this feature.

\subsection{Topicalisation}

The responses of the participant students on the recognition and preference of the BSAE feature known as topicalisation are also represented in figure 1 above. An example of the topicalisation as used in the questionnaire is illustrated in the following except (4):

Excerpt (4): Science students, they understand what global warming is. This global warming, it is dangerous to us.

Figure 1 above shows that $49 \%$ of the respondents agreed that topicalisation is a correct form, and that it is understandable. Its use would enhance the respondents' comprehension in Science and Mathematics. On the other hand, the perception of $51 \%$ of the respondents was that topicalisation would have a negative bearing on their understanding of the Science and Mathematics content. This feature of BSAE was the only one in the close-ended questions where there was no majority of the respondents indicating a conclusive bearing of the BSAE feature on their understanding of the Science and Mathematics content. An explanation could be found in the following observation. In BSAE literature, topicalisation also referred to as the use of the "resumptive pronoun" is permissible in the oral language of SBE (Makalela, 2004). Hence, in this article we are of the opinion that, it is this relative use both in BSAE and SBE that lends this feature its acceptability.

\subsection{Discourse markers}

Discourse markers as features of BSAE were also used to assess the respondents' recognition and preference of variety. An example of the usage of discourse markers as was used in the questionnaire is illustrated below in excerpt (5):

Excerpt (5): In fact, sufficient nitrogen in the soil produces healthy leaf growth. Actually, the leaves are so important to our health.

The perceptions of the respondents towards the discourse markers feature are also represented in figure 1 above which shows that $78 \%$ of the respondents concur that the discourse marker in fact is correctly used in excerpt (5), whereas $22 \%$ did not agree that it is correctly used. In SBE in fact and actually can be used for emphasis. However, in this case, there was no emphasis. The discourse markers, in fact and actually as used in excerpt (5) can be only be explained as indicators of the influence of mother tongue (Makalela, 2004). This is a situation where second language speakers transfer linguistic features from their mother tongue into the second language (Ellis, 1994). 


\section{Delineation of Results}

The analysis shows that the majority of the respondents recognised and preferred the use of BSAE linguistic properties in the learning of Science and Mathematics content. A further analysis to assess the gap between negative and positive scores of the feature recognition test was carried out. The scores for the Yes/ No categories were calculated cumulatively as shown in table 1 below:

Table 1: Total Scores of the Feature Recognition Test

\begin{tabular}{||l|c|c||}
\hline Category & Number of Yes & Number of No \\
\hline Question word order & 30 & 16 \\
\hline Extension of progressive aspect & 28 & 18 \\
\hline Preposition usage & 34 & 12 \\
\hline Topicalisation & 22 & 24 \\
\hline Discourse markers & 36 & 10 \\
\hline Total & $\mathbf{1 5 0}$ (Mean 80) & $\mathbf{8 0}$ (Mean 16) \\
\hline
\end{tabular}

Two sets of hypotheses were set as parameters; first, to judge the differences within the feature scores in both positive and negative columns; and second, the difference between the cumulative scores. The hypotheses were stated as follows:

Hypothesis 1:

- H0. There will not be differences between various linguistic feature scores in the positive column.

- H1. There will be differences between linguistic feature scores in the positive column.

Hypothesis 2:

- Ho. There is no difference of perceptions between the positive and negative responses.

- $\mathrm{H} 1$. There is a difference of perceptions between the positive and negative responses.

These hypotheses were tested through a Pearson chi-square, pitched at an alpha value of 0.05 . With regard to the first set of hypotheses, the chi-square test shown that the differences within each feature was statistically significant $\left(X^{2}=2 ; d f=4 ; P>0.05\right)$. This means that the null hypothesis was rejected. The results show that the positive attitudes skewed towards particular language features. The BSAE features. In this analysis the discourse feature that occurred more frequently than other features was topicalisation at 22 occurrences.

On the other pair of the hypotheses, the chi-squire value shown that the difference in perceptions between the positive and negative responses was statistically significant $\left(X^{2}=4 ; d f=4 ; P>0.05\right)$. These features are shared across a wide population. It is worth noting that the results do not only confirm institutionalisation of BSAE features within the group that participated in this study, but also show a high degree of preference for the BSAE features used to assess the participant students in this study. Observing this finding, the question whether or not there is a link between the participant's preferences and their perceptions on BSAE arises. The next section therefore presents a discussion on the results of the data analysis on the students' perceptions on BSAE.

\section{Perceptions on Black South African English}

It was indicated earlier that the second part of the questionnaire was employed to collect data on the student participants' perceptions of BSAE. Thematic analysis as recommended by (Braun \& Clarke, 2006) was employed to assess the various themes that emerged during the data analysis. To add emphasis to the data interpretation we quoted some responses verbatim to illustrate prototypical responses. 


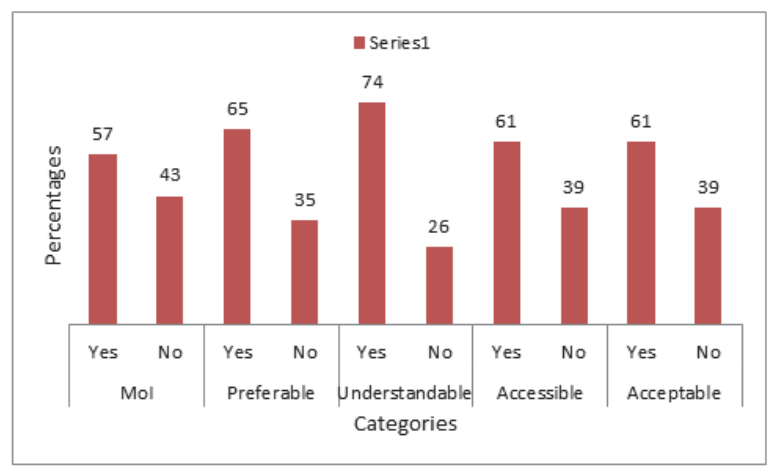

Figure 1: Perceptions of BSAE

\subsection{Use of BSAE as a medium of instruction}

The respondents were asked whether they thought it would be feasible to use BSAE as the medium of instruction instead of current attempts to stick with BSE norms in the teaching of Science and Mathematics. The figure (2) above illustrates percentages of whether or not learners would like BSAE to replace SBE.

Figure 2 show that $57 \%$ of the respondents agreed that BSAE should replace SBE in their learning of Science and Mathematics. Only 43\% did not think that replacing SBE would have any bearing on their understanding of the Science and Mathematics content. The results show that the majority of the respondents believe that the use of BSAE features would enhance their understanding in Science and Mathematics studies.

The results of the study show that a majority of the respondents were of the perception that they need to have BSAE as the medium of instruction. A prototypical response is illustrated in the argument shared in excerpt (6) below:

Excerpt (6) BSAE must be used as a medium of instruction because it is more like a mother tongue to blacks so it is gonna be much easier and understandable for us blacks if we use it as a medium of learning maths and Science.

The respondent in the preceding except shows that BSAE is perceived to be associated with mother tongue and that it has potential to serve as a substitute in the endeavour to use African languages in education. It can also be drawn from the above excerpt that the respondents perceive SBE a medium through which understanding and performance in the Science and Mathematics studies could be improved. Therefore, in our view, the respondent implies that BSAE could be used as an alternative medium of instruction for the teaching and learning of Science and Mathematics.

\subsection{Learners prefer to be taught in BSAE}

The respondents were asked if they would prefer to be taught in BSAE. From figure 2 above, if can be deduced that $65 \%$ of the respondents indicated their preference to be taught in BSAE whereas 35\% indicated that it may not be appealing to them to be taught in the medium of BSAE. During the thematic analysis, the following excerpt illustrates the perceptions which emerged during the analysis:

\section{Excerpt (7) I believe I will learn effectively in BSAE because I will be able to understand the meaning of the words.}

This response confirms what Buthelezi (1995) found in her study on lexical and syntactic items that BSAE speakers [like to] use locally relevant lexemes.

\subsection{BSAE is easier to understand than SBE}

A further finding was that the respondents indicated that they find BSAE easy to understand in the classroom than SBE. Figure 2 illustrates this as it shows that $74 \%$ of the respondents agreed that compared to SBE, BSAE is easy for South African black students to understand in their learning of Science and Mathematics. Only $26 \%$ did not think that BSAE would be easy to understand in their learning. The next except (8) below indicative of the predominant perception which emerged from this theme. 
Excerpt (8) Black South African English is easier to understand than British Standard English because it includes some aspects from our home languages.

The above excerpt (8) vividly captures what Makalela (2004) calls creative bilingualism, referring to a situation where a speaker juggles between two linguistic systems and creatively produces a well-formed and rule governed variety of English. The response implies that learning in BSAE would develop students' linguistic competence and enhance success in the learning of Science and Mathematics.

\subsection{SBE is accessible to South Africans}

The respondents were asked whether or not SBE is accessible to them as South Africans. To this, Figure 2 above shows that $61 \%$ of the respondents agreed that SBE is accessible to South Africans. Only 39\% did not think that SBE is accessible to South Africans. This result shows that although BSAE is a preferred variety of English, there is still a majority of the individuals who still perceive that SBE is accessible. As a result, a majority of the respondents argued that it should be maintained in the teaching and learning of Science and Mathematics. The following excerpt confirms this notion:

Excerpt (9): British Standard English is accessible; yes everyday we read, write and learn Science through it. It should be used in our classrooms

Although not directly mentioned, the above view carries with it the acknowledgement that SBE is still a language accessed only in written format, as it is 'read, written, and learned'. This indirectly acknowledges the lack of the variety in Science and Mathematics teachers' spoken language. This finding may be unfortunate in the light of Buthelezi (1995) who indicated study cited earlier that most non-standard features exhibited by the learners were teacher-induced. This shows that SBE is not accessible to all South Africans including teachers who are supposed to be models to learners. On the other hand, although in a minority (39\%), other respondents believed that SBE is not accessible to South Africans. This view was best captures in the excerpt below:

Excerpt (10) The British Standard English is (more) accessible in private schools and institutions than in public schools.

Even the teachers in public schools are not educated enough to use it.

The respondent in excerpt (9) above states that English is accessible to learners in private schools but not accessible to learners in public schools. In the same vein, Makalela (2004) indicates that macro acquisition of English and nativisation tendencies have found their footing in the global context where 80 percent of the speakers of English are non-traditional mother tongue speakers.

\subsection{Acceptance of Black South African English as a medium of instruction}

The concern in this section was to respond to the question on whether or not the respondents accept BSAE as a medium of instruction in their learning Science and Mathematics. From figure 2 above, it can be deduced that $61 \%$ of the respondents accept BSAE as a medium of instruction, whereas 39\% did not accept BSAE as a medium of instruction in their learning of Science and Mathematics. The results in this section show that the majority of the respondents accept that BSAE should be used as a medium of instruction in their learning of the Science and Mathematics content. The following excerpt (11) captures the respondents' perception about this theme:

Excerpt (11): I accept Black South African English because it will be easier to understand the methods and procedures of calculating/ solving the problems.

Looking at the quoted response, we could deduce that a number of respondents had a number of reasons (and perceptions) which informed acceptance of BSAE in teaching and learning. A further thematic analysis of these perceptions revealed the following fundamental reasons: that the use of BSAE has the potential to enhance understanding; that students are already exposed to the variety at an early age; that as learners encounter BSAE in their early age, they associate the variety with their mother tongue easily, a factor which according to cognitive theorists such as, Cummins and Swain, (1986) and Saville-Troike, (1991), contend that it aids the development of learners. Other perceptions or reasons in support of BSAE which emerged in the thematic analysis were as follows: the use of BSAE will 
increase the number of black people in Science sectors; BSAE will also contribute in improvement of students' pass rate in the Science stream

\section{Conclusion}

The conclusion drawn from the results of this study, shows that learners recognize BSAE features as acceptable. This includes retention of question word order, extension of progressive aspect to stative verb, Preposition usage in prepositional verb, topicalisation, and discourse markers. Their perceptions towards BSAE show that they prefer BSAE for teaching and learning of Science and Mathematics content. The perceptions of Science and Mathematics students focused on use of BSAE as a medium of instruction, learners' preference to be taught in BSAE, the investigation found that according to the participants in this study compared to SBE, BSAE was found easy for the students and thus preferred in South African classroom. This could be coupled with the fact that the study found BSAE to be accessible to the participant students. Hence, its general acceptance as a medium of instruction. Various reasons for the acceptance of BSAE were given by the participant students' revealing a number of perceptions.

Therefore, considering the fact that the results of this study indicate that BSAE is a preferable variety of English amongst Science and Mathematics students. We recommend that inclinations towards SBE in South African Science and Mathematics classrooms be superseded by opting for BSAE instead.

\section{References}

Berns, M. (1995). English in the European Union. English Today, 11 (3), 3 -11.

Braun, V. \& Clarke, V. (2006) Using thematic analysis in psychology. Qualitative Research in Psychology, 3(2), 77-101.

Brutt-Griffler, J. (2002). World English: A study of its development. Buffalo: Multilingual Matters.

Buthelezi, Q. (1995). South African Black English: Lexical and syntactic characteristics. In R Mesthrie (Ed.) Language and social history: Studies in South African Sociolinguistics, (pp. 242 -250). Cape Town: David Philip.

Buxton, C. (1998). Improving the Science education of English language learners: Capitalising on educational reform. Journal of women and Minorities in Science and Engineering, 4(4), 341- 363.

Buxton, C., Allexsaht-Snider, M., \& Rivera, C. (2012). Science, language and families: Constructing a model of language-rich Science inquiry. In J. Bianchini, V. Atkerson, A. Calebrese Barton, O. Lee, \& A. Rodriguez (Eds.), Moving the equity agenda forward: Equity research, practice and policy in Science education (pp. 241-259). New York: Springer.

Crystals, D. (1997). English as a global language. Cambridge: Cambridge University Press.

Cummins, J. and Swain, M. (1986). Bilingualism in Education. London: Longman.

De Klerk, V and Gough, D. (2002). Black South African English. In R Mesthrie (Ed) language in South Africa (pp. 356-78). Cambridge: Cambridge University Press.

Ellis, R. (1994). The study of second language acquisition. Oxford: Oxford University Press.

Gage, W. (1986). The world balance of languages. In J.A. Fishman, A. Tabouret-keller, M. Clyne, B.H. Krishnamurti, and abdullaziz (Eds.), The Fergusonian impact (pp. 371-383). Berlin: Mouton de Gruyer.

Gall, M.D., Borg, W.R., and Gall, J.P. (1996). Educational Research: An introduction. New York, Longman.

Geay, C., McNally, S. \& Telhaj, S. (2013). Non-native Speakers of English in the Classroom: What Are the Effects on Pupil Performance? The Economic Journal, 123(570), F281 - F307.

Gough, D. (1994). Thinking in Xhosa and speaking in English the theory and practice of contrastive analysis. Paper presented at the First World Congress of African linguistics, University of Swaziland.

Gough, D. (1996). Black English in South Africa. In V. de Kerk (Ed.), Varieties of English around the World (pp. 53 -77) Amsterdam: John Benjamins.

Kachru, B.B. (1985). Standards, codification and sociolinguistics realism: the English language in the outer circle. In R. Quirk \& Y. Cantù (Eds.), English in the world: Teaching and Learning the languages and Literature. (pp. 11-30) Cambridge: Cambridge University Press.

Kachru, B.B. (1992). The other tongue: English across cultures. Champaign: University of Illinois Press.

Kamwangamalu, N.M. \& Chisanga T. (1997). Owning the Other tongue: The English Language in South Africa. Journal of Multilingual and Multicultural Development. 18(2), 89-98.

Kasanga, L.A. (2005). English(es) and the global context: The changing face of lingua franca under siege. Belgium Journal of English language and literature. 3(1/4), 161-181.

Kasanga, L.A. (2006). Request in South African variety of English. In World Englishes, 25(1), 65-89.

Lee.O. \& Fradd, S.H. (1998). Science for all, including students from non-English language backgrounds. Educational Researcher, $27(4), 12-21$.

Mabila, T. E.; Malatje, S. E.; Addo-Bediako, A.; Kazeni, M. M. M.; Mathabatha, S. S. (2006). The Role of Foundation Programmes in Science Education: The UNIFY Programme at the University of Limpopo, South Africa. International Journal of Educational Development, 26(3), 295-304. 
Makalela, (2007). Nativization of English among Bantu language speakers in South Africa. Issues in applied linguistics, 15(2), $129-147$. Makalela, L. (1998). Institutionalized Black South African English. National Association of Educators of Teachers of English, 23(3), 5871.

Makalela, L. (2004). Making Sense of BSAE for linguistic democracy in South Africa. World Englishes, 23(3), 355-366.

Makoni, S. (1993). Multiple forces on new English. UNISWA Research Journal, 7:23-32.

McEwan, M.J. (1992). A comparative study in grammatical competence of Standard ten English Second language learners from different native language backgrounds, namely English and Afrikaans. Unpublished Honours essay. Grahamstown. Rhodes University.

Mothoa, S. (2001). Grammatical features of Black South African English as examplified in the written samples of Ndebele and Northern Sotho first language speakers. Unpublished, MA dissertation. Polokwane. University of the North.

Moyo, T. (1994). The influence of isizulu on ESL students. Crux, 28(1), 59-64.

Ntlhakana, P. (2000). People's English. English Today, 16(2), 11-17.

Parkinson, J. \& Singh, V. (2007). Stability of grammatical features of Black South African English. Per linguam, 23(2), 54-67.

Pennycook, A. (2003). Global Englishes, Rip Slyme, and performativity. Journal of Sociolinguistics, 7(4): 513-533.

Sato, T. \& Suzuki, A. (2007). Diagnosing factors of the preference for English as a center variants of English in English as a lingua franca settings. Journal of English as an international language, 2, $50-64$.

Saville-Troike, M. (1991). Teaching and testing for academic achievement: The role of language development. NCBE Focus: Occasional papers in bilingual education. Retrieved from http://www.ncbe.gwu.edu/ncbepubs/focus/focus4.htm

Silva, P. (2005). South African English: Oppressor or Liberator? In H. Linguist, S. Klintborg, M. Levin, \& M. Estling (Eds.). The major varieties of English: Papers from MAVEN 97, 79 -92. Vaxjo: Vaxjo University Press.

Stepanek, S.J. (1989). Learning English in Mathematics and Science classroom. Retrieved from http://nwrel.org/msec/nwteacher/ winter2004/barrires.html.

Titlestad, P. (1997). Appropriate English in South Africa. In V. Webb (Ed.) Appropriate English in democratic South Africa. Pretoria: University of Pretoria, 10-17.

Van Rooy, B. (2006). The extension of the progressive aspect in Black South African English. In World Englishes, 25(1), 65-89.

Warren, B., Ballenger, C., Ogonowki, M., Rosebery, A.S., \& Hudicourt-Barnes, J. (2001). Rethinking diversity in learning Science: The logic of everyday sense-making. Journal of Research in Science Teaching, 38(5), 529-552. 